\title{
Retraction
}

\section{Retracted: Marathon Runner with Acute Hyponatremia: A Neurological Disorder}

\author{
Case Reports in Emergency Medicine \\ Received 13 February 2019; Accepted 13 February 2019; Published 26 March 2019 \\ Copyright (C) 2019 Case Reports in Emergency Medicine. This is an open access article distributed under the Creative Commons \\ Attribution License, which permits unrestricted use, distribution, and reproduction in any medium, provided the original work is \\ properly cited.
}

At the request of the authors, the article titled "Marathon Runner with Acute Hyponatremia: A Neurological Disorder" [1] has been retracted. The article was previously published as "Kormann R, Philippart F, Hubert S, Bruel C, "Marathon Runner with Acute Hyponatremia: A Neurological Disorder”. Emerg Med (Los Angel) 2:106, (2012). doi:10.4172/2165$7548.1000106 "$ " [2].

\section{References}

[1] R. Kormann, F. Philippart, S. Hubert, and C. Bruel, "Marathon runner with acute hyponatremia: a neurological disorder," Case Reports in Emergency Medicine, vol. 2012, Article ID 342760, 3 pages, 2012.

[2] R. Kormann, F. Philippart, S. Hubert, and C. Bruel, "Marathon runner with acute hyponatremia: a neurological disorder," Emergency Medicine: Open Access, vol. 2, no. 106, 2012. 


\title{
Marathon Runner with Acute Hyponatremia: A Neurological Disorder
}

\author{
R. Kormann, ${ }^{1}$ F. Philippart, ${ }^{2,3}$ S. Hubert, ${ }^{1}$ and C. Bruel ${ }^{2}$ \\ ${ }^{1}$ Internal Medicine, Groupe Hospitalier Paris Saint Joseph, 75014 Paris, France \\ ${ }^{2}$ Intensive Care Unit, Groupe Hospitalier Paris Saint Joseph, 75014 Paris, France \\ ${ }^{3}$ Paris Descartes University, 75006 Paris, France
}

Correspondence should be addressed to S. Hubert, shubert@hpsj.fr

Received 9 February 2012; Accepted 7 March 2012

Academic Editors: C.-C. Lai, M. Sand, and H. P. Wu

Copyright () 2012 R. Kormann et al. This is an open access article distributed under the Creative Commons Attribution License, which permits unrestricted use, distribution, and reproduction in any medium, provided the original work is properly cited.

\begin{abstract}
We report the case of an athletic 49-year-old female who has run the 2011 Marathon of Paris and was addressed to the hospital for a confusion. The investigations revealed a cerebral edema complicating a severe hyponatremia secondary to an exercise-associated hyponatremia (EAH). Using 3\% hypertonic saline solution, the evolution the patient rapidly improve allowing discharge after 7 days. We then discuss the importance of EAH in long-term efforts.
\end{abstract}

\section{Introduction}

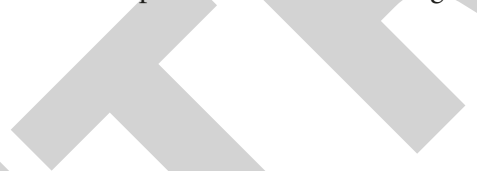

Marathons, and more widely long-term efforts attract more and more nonprofessional runners (popular festive events and charity runs). Due to this modification of population behavior, pathologies associated with high-level sport practices tend to take a huger place in emergency clinical practice. Among them, exercise-associated hyponatremia (EAH) is a very important one.

\section{Case Presentation}

We report the case of an athletic 49-year-old female with no medical records who has run the 2011 Marathon of Paris $(42.195 \mathrm{Km})$. In view of the marathon, the patient started to train a few months ahead as per two to three runs weekly. She completed the marathon within $5 \mathrm{~h} 30$, with an average speed of $7.5 \mathrm{Km} / \mathrm{h}$, on a warm day ( 27 degrees celsius). Along the run, she drunk $4 \mathrm{~L}$ of mineral water $(5 \mathrm{mg} / \mathrm{L} \mathrm{NaCl})$, and had some energy bars at the various feeding stations. Four hours after completion of the marathon, the patient felt dizzy and nauseous, with a strong asthenia and encompassed three vomiting periods associated with disorientation and confusion. She was then admitted to the emergency room 7 hours after the afore-mentioned symptoms occurred.
Upon admission, the patient was conscious but disoriented, clouded, with a Glasgow coma score of 13. She was apyretic and presented no circulatory failure. The neurological examination revealed acute spreadover of osteotendinous reflexes the four limbs, no systematic deficiencies and cutaneous plantar reflexes in flexion, isochoric and reactive pupils. Her body weight was $53.4 \mathrm{Kg}$ (normal average body weight of $50 \mathrm{Kg}$ ).

The patient was then transferred to the intensive care unit (ICU) for diagnosis and treatment. Four hours later, the patient had a generalized tonic-clonic seizure that resolved following $1 \mathrm{mg}$ clonazepam IV injection. The cerebral CT-scan showed a diffused supratentorial cerebral oedema (Figure 1). The initial biological parameters were natremia $121 \mathrm{mmol} / \mathrm{L}$, chloremia $88 \mathrm{mmol} / \mathrm{L}$, protidemia $70 \mathrm{~g} / \mathrm{L}$, glycemia $8.5 \mathrm{mmol} / \mathrm{L}$, kalemia $3.3 \mathrm{mmol} / \mathrm{L}$, bicarbonates $18 \mathrm{mmol} / \mathrm{L}$, blood urea nitrogen $3.7 \mathrm{mmol} / \mathrm{L}$, creatinemia $68 \mu \mathrm{mol} / \mathrm{L}$, blood urea nitrogen $2.9 \mathrm{mmol} / \mathrm{L}$, uric acid $214 \mathrm{mmol} / \mathrm{L}$, Glycemia $6.6 \mathrm{mmol} / \mathrm{L}$, calcemia $1.8 \mathrm{mmol} / \mathrm{L}$, phosphorus $0.87 \mathrm{mmol} / \mathrm{L}$, magnesemia $1.04 \mathrm{mmol} / \mathrm{L}, \mathrm{CPK}$ $14486 \mathrm{UI} / \mathrm{L}, \mathrm{Hb} 10.1 \mathrm{~g} / \mathrm{dL}$, platelet count $172 \mathrm{G} / \mathrm{L}$, and leukocytes $11.06 \mathrm{G} / \mathrm{L}$. The calculated osmolality was $260 \mathrm{mosm} / \mathrm{kg}$ and the measured osmolality was $246 \mathrm{mosm} / \mathrm{kg}$. Arterial blood gases showed a respiratory alkalosis to compensate an increased plasmatic anion gap metabolic acidosis, 


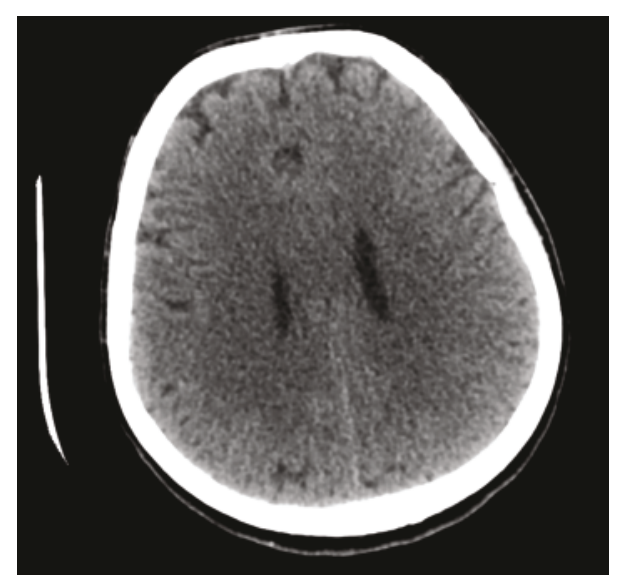

FIgURE 1: Noninjected CT-scan realized on the day of admission.

with initial blood lactate $10.5 \mathrm{mmol} / \mathrm{L}$. The initial collection of a urine sample showed an urinary osmolality of $489 \mathrm{mosm} / \mathrm{L}$. We report a natriuresis and kaliuresis of 86 and $75 \mathrm{mmol} / \mathrm{L}$, respectively. The measure of the free cortisol was $1250 \mathrm{nmol} / \mathrm{L}$ at $8 \mathrm{am}$, and $1350 \mathrm{nmol} / \mathrm{L}$ following the ACTH test, by which therefore eliminate an adrenal origin of hyponatremia.

The patient was given a calculated bolus of isotonic saline as per the Adrogue formula. As no further clinical improvements followed, with a persistent hyponatremia of $121 \mathrm{mmol} / \mathrm{L}$, the patient was given a treatment based on $3 \%$ hypertonic saline solution. Natremia was recorded and indicated $128 \mathrm{mmol} / \mathrm{L}$ and $136 \mathrm{mmol} / \mathrm{L}$ at 4 hours and 7 hours after beginning of the treatment, respectively. Despite a rapid correction of natremia abnormalities, biological improvement was associated with the resolution of the neurological perturbations without apparition of new neurological symptoms.

The patient was discharged after 7 days following complete resolution of clinical and biological disorders.

\section{Discussion}

The clinical and biological context is a physical exerciseassociated hyponatremia (EAH) as defined by a plasmatic sodium concentration below $135 \mathrm{mmol} / \mathrm{L} 24 \mathrm{~h}$ following a prolonged physical activity $[1,2]$. Marathons attract plenty of nonprofessional runners like our patient who ran her first marathon at the age of 49. Risk factors in favor of EAH occurrence can be merged into two groups: (i) runner condition-associated factor (female, low body weight, lack of training, slow runner, excessive drinking consumption during the run, and NSAIDS consumption); (ii) environmentrelated factors (prolonged physical activity of over $4 \mathrm{~h}$, warm air temperature, and drinks availability along the run [3]).

This syndrome, first described in 1981 [1], is closely related to an evolution in high-level sport practices (marathon; triathlon) and the concept of abundant hydration during the activity in order to reduce dehydratation and hypernatremia risks [4]: an overdrinking consumption during and after the run, and the related occurrence of a syndrome of inappropriate secretion of antidiuretic hormone (SIADH). The excessive drinking consumption during activity is the primary and critical risk factor associated to EAH occurrence $[4,5]$. Then, it has been shown that the risk to develop an EAH is correlated to an increase of body weight during the physical activity as observed in the present patient $(+3,4 \mathrm{Kg})$. There are no indications of a thirst deregulation among runner, as thirst is a late adaptation mechanism in this particular regulation system [6]. Despite this, the hyperhydratation during activity on its own cannot resume hyponatremia. The kidneys can excrete 750 to $1500 \mathrm{~mL} / \mathrm{h}$ of water in normal physiological conditions [7]. ADH is a hormone secreted by the hypothalamus and is subject to stimulation upon low charges (1-2\%) in the plasmatic osmolality [8]. In addition to the osmotic stimulation, other mechanisms inducing the central production of $\mathrm{ADH}$ have been described: nausea, vomiting organic stress, pain and endorphins, volemic status, central temperature increase, or hypoxia $[2,4,6-9]$. The excess of $\mathrm{ADH}$ production is responsible for potentially serious hyponatremia as described by Siegel et al. [10] and recognized as a key factor for the EAH occurrence $[2,4,7$, $9,10]$. Moreover, It has been suggested that cytokines release (IL6) could also be involved in the nonosmotic stimulation of $\mathrm{ADH}[7,9]$. A rapid decrease of natremia $(<128 \mathrm{mmol} / \mathrm{L})$ is correlated with the emergence of serious clinical alterations, notably neurological disorders following brain swelling [3], as described in the present patient. Patients associated with symptomatic EAH and subsequent serious neurological (confusion, vigilance disorders, coma, and tonicclonic seizures) or pulmonary (acute respiratory failure) disorders should imperatively be transferred to ICU with a repeated surveillance as the natremia. Acute hyponatremia treatment can benefit of a novel concept associated with a remarkable therapeutic efficiency $[2,4,7,9,10]$. Treatment of serious EAH conditions involve the administration of a $3 \%$ hypertonic saline solution at $1 \mathrm{~mL} / \mathrm{kg} / \mathrm{h}$, that is subsequently adjusted following natremia status. Increases of natremia to $1 \mathrm{mmol} / \mathrm{L} / \mathrm{h}$ during the first $6 \mathrm{~h}, 9 \mathrm{mmol} / \mathrm{L}$ during the first $24 \mathrm{~h}$, and $18 \mathrm{mmol} / \mathrm{L}$ during the first $48 \mathrm{~h}$ are accepted. Ideally, natremia should not evolve over $20-25 \mathrm{mmol} / \mathrm{L}$ during the first $48 \mathrm{~h}[5,10]$. The isotonic saline solution appears inefficient for the treatment of EAH as described in a previous study [4] and as observed in the present case, in which no noticeable positive biological response was detected following initial administration of saline.

The EAH prevention relies on information regarding hyperhydratation risks during the run and the necessity to control water supplies in a range of $400-700 \mathrm{~mL} / \mathrm{h}$, depending on body weight and weather conditions [5]. Beltrami has described the historical link between overdrinking during a prolonged and intensive sport activity and the occurrence of hyponatremia. This overdrinking behavior seems to be supported by sport drinks selling companies. Moreover, these sport drinks (enriched solutions with mineral salts and ions, slightly less hypotonic than mineral water) do not prevent EAH, neither is the sodium supplier by systematic per os intake [3]. 


\section{Conclusion}

In summary, EAH is associated to a SIADH which the severity is as high as the hydric supply during and after the physical activity, occurring during or in the few hours following the activity. It could sometimes evolve as critical emergency situation with signs of neurological disorders, and the only efficient treatment consists of the administration of hypertonic saline solution. The prevention strategy consists in informing runners on good hydration practices during the run and the hyperhydratation-associated risks.

\section{References}

[1] T. D. Noakes, N. Goodwin, B. L. Rayner, T. Branken, and R. K. N. Taylor, "Water intoxication: a possible complication during endurance exercise, 1985," Wilderness \& Environmental Medicine, vol. 16, no. 4, pp. 221-227, 2005.

[2] A. J. Siegel, J. G. Verbalis, S. Clement et al., "Hyponatremia in marathon runners due to inappropriate arginine vasopressin secretion," The American Journal of Medicine, vol. 120, no. 5, pp. 461.e11-461.e17, 2007.

[3] T. Hew-Butler, J. C. Ayus, C. Kipps et al., "Statement of the second international exercise-associated hyponatremia consensus development conference, New Zealand, 2007," Clinical Journal of Sport Medicine, vol. 18, no. 2, pp. 111-121, 2008.

[4] T. D. Noakes, K. Sharwood, D. Speedy et al., "Three independent biological mechanisms cause exercise-associated hyponatremia: evidence from 2,135 weighed competitive athletic performances," Proceedings of the National Academy of Sciences of the United States of America, vol. 102, no. 51, pp. 18550 18555, 2005.

[5] T. D. Noaken, G. Wilson, D. A. Gray, M. I. Lambert, and S. C. Dennis, "Peak rates of diuresis in healthy humans during oral fluid overload," South African Medical Journal, vol. 91, no. 10, pp. 852-857, 2001.

[6] J. G. Verbalis, "Disorders of body water homeostasis," Best Practice \& Research, vol. 17, no. 4, pp. 471-503, 2003.

[7] M. H. Rosner and J. Kirven, "Exercise-associated hyponatremia," Clinical Journal of the American Society of Nephrology, vol. 2, no. 1, pp. 151-161, 2007.

[8] R. W. Schrier, "Body water homeostasis: clinical disorders of urinary dilution and concentration," Journal of the American Society of Nephrology, vol. 17, no. 7, pp. 1820-1832, 2006.

[9] A. J. Siegel, "Exercise-associated hyponatremia: role of cytokines," The American Journal of Medicine, vol. 119, no. 7, supplement 1, pp. S74-S78, 2006.

[10] A. J. Siegel, "Hypertonic (3\%) sodium chloride for emergent treatment of exercise-associated hypotonic encephalopathy," Sports Medicine, vol. 37, no. 4-5, pp. 459-462, 2007.

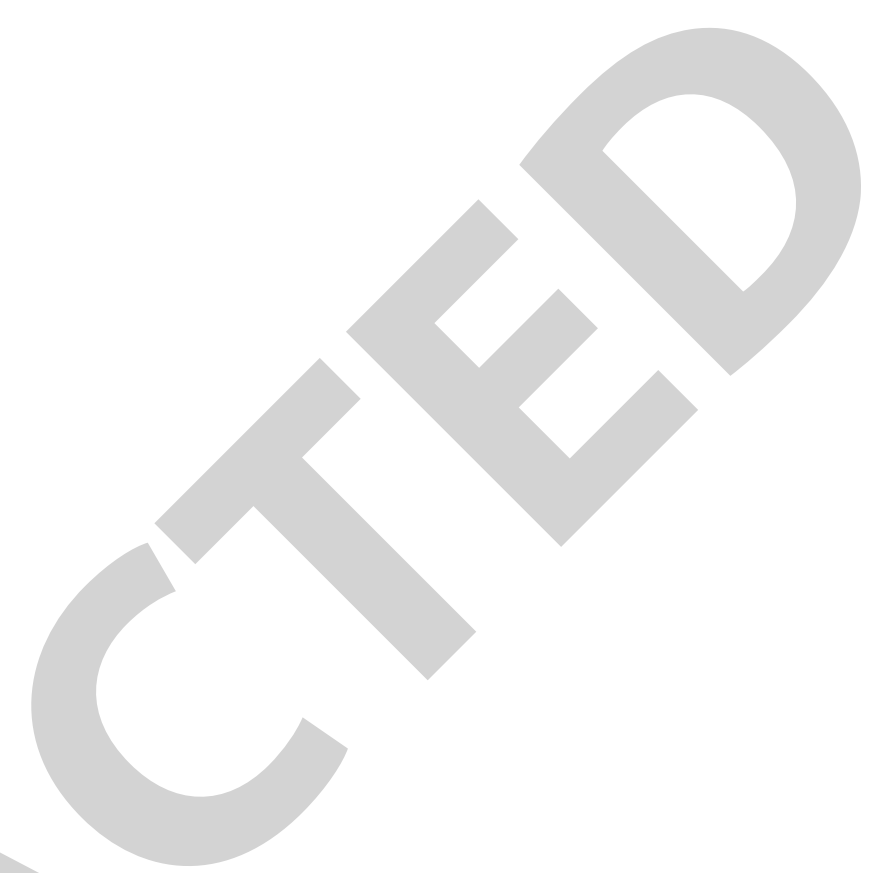

